\title{
IMAGENS AÉREAS OBTIDAS EM VÔOS COMERCIAIS COMO RECURSO METODOLÓGICO PARA O ESTUDO DA PAISAGEM E DO TERRITÓRIO
}

\author{
Tuane Telles Rodrigues $^{(\mathrm{a})}$, Cibele Stefanno Saldanha ${ }^{(\mathrm{b})}$, Letícia Ramires Corrêa ${ }^{(\mathrm{c})}$ \\ (a) Departamento de Geociências/Curso de Pós-Graduação em Geografia, Universidade Federal de Santa Maria, \\ tuanytel@ hotmail.com \\ (b) Departamento de Geociências/Curso de Pós-Graduação em Geografia, Universidade Federal de Santa Maria, \\ cyka_stefanno@hotmail.com \\ (c) Departamento de Geociências/Curso de Pós-Graduação em Geografia, Universidade Federal de Santa \\ Maria,leticiarcorrea@gmail.com
}

\section{Eixo: GEOTECNOLOGIAS E MODELAGEM ESPACIAL EM GEOGRAFIA FÍSICA}

\begin{abstract}
Resumo
As imagens aéreas são um recurso valioso para a análise do espaço, e com frequência utilizamos imagens obtidas por satélites ou por sensores de alta precisão. Esta pesquisa buscou avaliar a legalidade de imagens obtidas por câmeras digitais presentes em dispositivos móveis, quando capturadas também em aeronaves. Utilizando como amostra para análise a paisagem presente entre os aeroportos da cidade de São Paulo e Goiânia. Tendo como objetivo principal, revelar como esse recurso pode ser eficiente para a análise do espaço quando consideramos algumas questões, como a leitura geográfica do espaço, e noções de escala a partir da altura em que a aeronave se encontra. A metodologia utilizada apoiou-se nos estudos sobre o tema proposto, noções sobre altura de voo, captura das imagens e posterior análise das mesmas. Os resultados mostraram que, quando devidamente utilizadas, as imagens digitais obtidas por dispositivos móveis (mobile) proporcionam uma eficaz análise do espaço.
\end{abstract}

Palavras chave: Imagens aéreas; Análise espacial; Recurso Metodológico.

\section{Introdução}

As imagens aéreas são um recuso importante para as análises do espaço, nos ajudam a reconhecer os agentes naturais ou antrópicos responsáveis pela mudança do espaço.

No sensoriamento remoto faz análise de dados a partir dos processos de interpretação de imagens de satélite ou de fotointerpretação por meio visual (Novo, 1995, p. 6). Essa forma analítica pode ser desenvolvida por diferentes técnicas, entre as quais, a fotogrametria que obtém alcances precisos de objetos, obtendo das fotografias informações geométricas e quantitativas e a fotointerpretação que identifica e determina os objetos por meio de fotografias, alcançando informações qualitativas.

Cruz (1981, p. 1) apud.Panizza e Fonseca (2011) destacou no início na década de oitenta a utilização do sensoriamento remoto no levantamento de dados sobre recursos naturais, devido à intensa demanda 


\section{OS DESAFIOS DA GEOGRAFIA FÍSICA NA FRONTEIRA DO CONHECIMENTO \\ Instituto de Geociências - Unicamp \\ Campinas - SP \\ 28 de Junho à 02 de Julho de 2017}

e a degradação destes, nas mais diferentes escalas expondo a necessidade de planejamento em direção ao uso sustentável.

Segundo Florenzano (2002) nos anos 1960, os satélites tripulados proveram as primeiras fotografias orbitais da Terra e em seguida, o satélite meteorológico iniciou os registros sistemáticos de imagens da superfície terrestre.

Para nos auxiliar sobre como as imagens deveriam ser registradas, nos apoiamos em Panizza e Fonseca (2011) ao nos dizer que a posição do observador ou que tira a fotografia determina a forma de apreensão da paisagem a ser estudada, nesse contexto destacam-se as seguintes posições e perspectivas: a) Frontal: apreensão horizontal assemelha-se aquela dos quadros e também da visão do observador no solo; b) Panorâmica: apreensão oblíqua, como a dos mirantes que proporcionam a visão do observador localizado num nível mais alto àquele da paisagem observada; c) Voo de pássaro: apreensão por meio de uma visão vertical, semelhante àquela observada de um avião; d) Cinemática: apreensão da paisagem em "movimento". Permite a detecção de eventuais transformações ocorridas em lapsos de tempo.

Com base na posição "vôo de pássaro" que atribuímos nossa pesquisa, onde consideramos que para fotografar uma área, o avião voa em determinada direção (linha de voo), porém sem considerar questões de grande habilidade e recursos que permitem uma varredura da área onde a aeronave retorna na direção contrária ocorrendo a superposição de fotografias na visão esterocópia. (Cruz, 1981, p. 6)

O número da faixa e da fotografia é essencial na constituição do foto-índice, que tem por função localizar geograficamente a sequência das fotografias (Cruz, 1981, p. 8). Para que consigamos estabelecer a posição geográfica de um determinado ponto quando fotografamos de dentro de uma aeronave comercial, podemos utilizar apenas objetos simples que não transmitam ondas, já que o uso de GPS é proibido.

Apoiamo-nos nas palavras de Santos (1996) ao dizer-nos que os objetos de interesse à Geografia não são exclusivamente objetos móveis, mas também o imóvel, como uma cidade, ou uma barragem, uma estrada, um porto, uma floresta, uma plantação, um lago ou uma montanha, pois tudo isso são objetos geográficos e esses objetos são do domínio tanto da Geografia física quanto da Geografia humana e através da história desses objetos. E para Cazabat, C., 1969 apud Pinchemel; Pinchemel, (1988, p.357) "Os diferentes elementos de uma estrutura foram inseridos e organizados no espaço sob a influência de diversas forças e em diferentes momentos".

Segundo Penteado (1991) as imagens podem ser trabalhadas de formas diferenciadas, dependendo do recurso tecnológico utilizado como a imagem de uma foto por ser imóvel, recorta um fato e o isola do seu contexto, sendo assim uma única imagem pode ser aproveitada como material pedagógico dentro de várias temáticas. 
XVII Simpósio Brasileiro

de Geografia Fisica Aplicada

I Congresso Nacional

de Geografia Física

\section{OS DESAFIOS DA GEOGRAFIA FÍSICA NA FRONTEIRA DO CONHECIMENTO \\ Instituto de Geociências - Unicamp \\ Campinas - SP \\ 28 de Junho à 02 de Julho de 2017}

\section{Desenvolvimento}

Os recursos tecnológicos modernos são amplamente utilizados como parte de metodologias de pesquisas que visam o estudo espacial, e o acesso fácil a este instrumento propõe o uso abundante por uma grande parte da população brasileira. Alguns destes recursos podem auxiliar tanto cientistas e pesquisadores quanto amadores entusiastas. Porém, o desenvolvimento da habilidade em ler o que se observa é algo de grande relevância para compreender a imagem do espaço registrado e esta habilidade apenas desenvolve-se com base nos conceitos fundamentais sobre o estudo na natureza.

Este estudo ocorreu durante o percurso de um vôo comercial entre o aeroporto de Congonhas (CGH) na capital paulista São Paulo, e o aeroporto de Goiânia, Santa Genoveva (GYN), percorrendo uma distância de aproximadamente 805,20 Km.

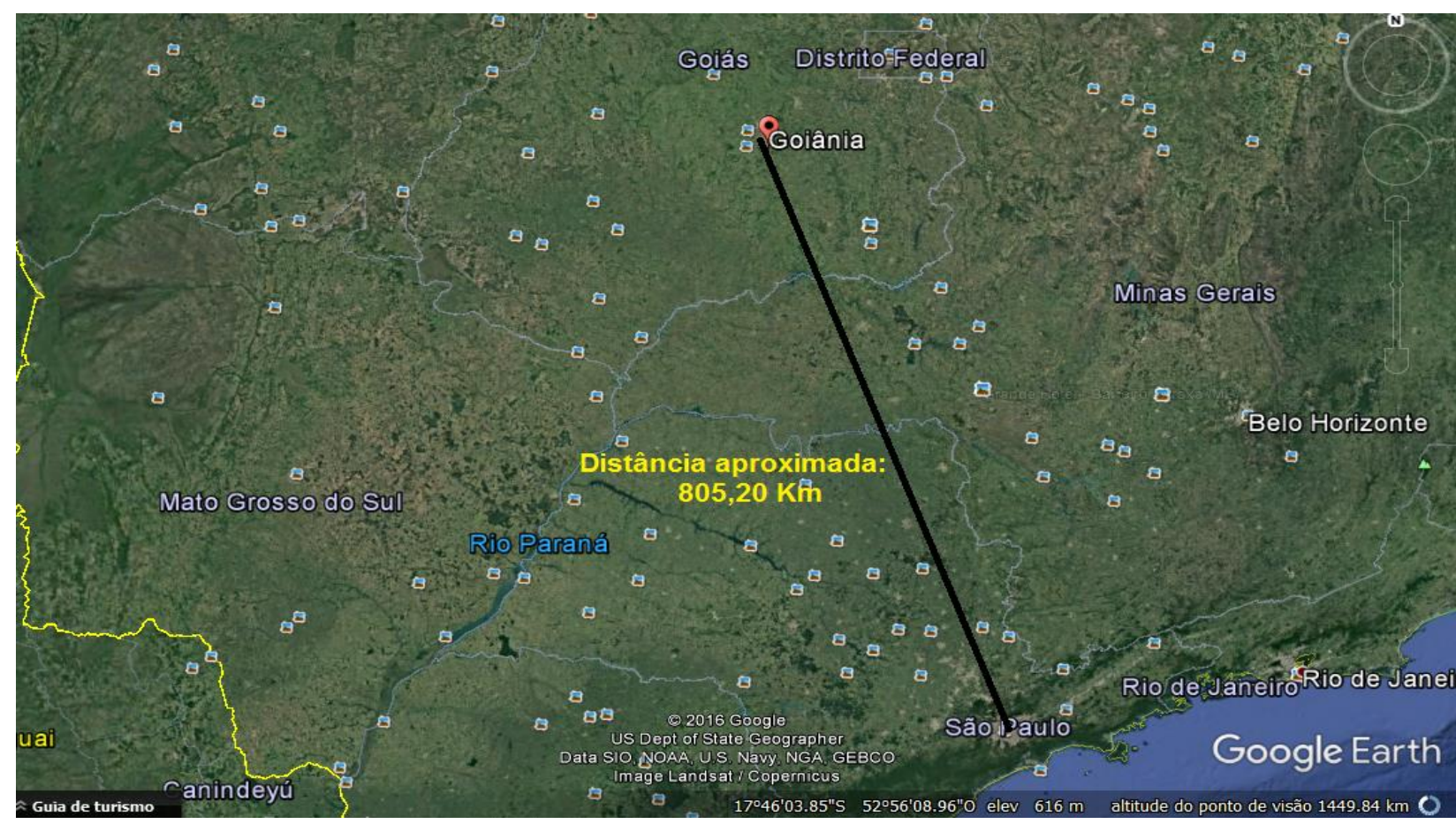

Imagem 1- Percurso do vôo e distância aproximada entre os dois pontos. Fonte: Google Earth, adaptado por Rodrigues, Tuane T. (2016).

Para a pesquisa escolhemos a linha comercial da empresa Gol-Linhas Aérea, pois esta empresa possui autorizaçãodesde sete de Julho de 2015 da Agência Nacional de Aviação Civil (Anac) para utilização de dispositivos móveis apenas em "modo avião".

Esta pesquisa fundamentou-se na possibilidade de leitura e interpretação de imagens e na possibilidade de utilizar recursos de uso comum como ferramentas para a captura de imagens espaciais, considerando que a reposição de fotografias digitais obtidas por dispositivos móveis, promovem 


\section{OS DESAFIOS DA GEOGRAFIA FÍSICA NA FRONTEIRA DO CONHECIMENTO \\ Instituto de Geociências - Unicamp \\ Campinas - SP \\ 28 de Junho à 02 de Julho de 2017}

atualizações mais frequentes dos registros de uma determinada área de estudo, podendo auxiliar na identificação de seus agentes.

Outra característica importante considerada foi o avanço no desenvolvimento da alta resolução e adaptação as condições da luminosidade do ambiente que garantem melhor qualidade dos registros.

Para nós geógrafos que sabemos importância da escala em uma imagem, podemos fazer uso de noções de altitude de vôo para estabelecer o melhor momento de registrar a imagem de um território.

Os aviões comerciais, que representam a grande maioria das aeronaves no céu, voam a altitude de cruzeiro, cerca de 11.000 metros. Essa é a altitude em que o avião consegue gastar menos combustível, pois o ar se torna menos denso e por isso oferece menor resistência, portanto, há uma máxima no nível de escala pequena que podemos registrar.

\section{Procedimentos Metodológicos}

Ao traçarmos como objetivo principal, mostrar e discutir sobre a eficiência da utilização das câmeras portáteis presentes nos dispositivos móveis como recurso para a análise do espaço, estabelecemos alguns parâmetros primordiais para captura e posterior análise dos produtos obtidos, como a leitura geográfica do espaço, e noções de escala a partir da altura em que a aeronave se encontra.

A primeira etapa metodológica consistiu em uma pesquisa bibliográfica, para levantamento dados referentes ao projeto que se pretendeu realizar, e análise técnica sobre as possibilidades em capturar imagens utilizando dispositivos móveis, bem como se havia preferência quanto ao modelo do aparelho e testes de transmissão de ondas sobre estes dispositivos.

A segunda etapa baseou-se na escolha do local a ter as imagens capturadas, elegemos o percurso. São Paulo (aeroporto de Congonhas) e Goiânia (aeroporto Santa Genoveva) no dia 7 de Outubro de 2016, pelo contraste entre a paisagem, urbana na cidade paulista e campesina principalmente nas regiões de divisa entre Minas Gerais e Goiás.

Utilizamos a câmera do smartphone Sony Xperia C, devido a testes realizados anteriormente com outras câmeras digitais que não apresentaram a mesma resolução e capacidade de regulamento no foco e precisão.

As imagens capturadas contemplaram as seguintes possibilidades de análise: Ocupação territorial, espaço urbano ou rural, desgaste da cobertura vegetal, variabilidade de espécias arbóreas, bacias hidrográficas, extração mineral, recursos hídricos entre outros. 


\section{OS DESAFIOS DA GEOGRAFIA FÍSICA NA FRONTEIRA DO CONHECIMENTO \\ Instituto de Geociências - Unicamp \\ Campinas - SP \\ 28 de Junho à 02 de Julho de 2017}

Estabelecemos uma tabela para classificar as fotografias, a partir da apresentação ou não de determinados elementos e assim estabelecer grupos para melhor analisá-las:

Tabela I- Elementos classificação.

\begin{tabular}{|c|c|}
\hline \multicolumn{1}{|c|}{ Tabela de elementos } & Marque SIM ou NÃO. \\
\hline 1. $\quad$ A imagem representa uma área urbana? & \\
\hline 2. A imagem representa uma área rural? & \\
\hline 3. A imagem possui escala geográfica grande? & \\
\hline 4. A imagem possui uma escala geográfica pequena? & \\
\hline 6. A imagem possui recursos hídricos? & A imagem possui área de densa cobertura vegetal? \\
\hline 7. A imagem aparenta de áreas com solo exposto? & \\
\hline 8. Havia grande incidêcia direta de radiação solar? & \\
\hline 9. A imagem apresenta nuvens? & \\
\hline $\begin{array}{l}\text { Região: } \\
\text { Local: }\end{array}$ &
\end{tabular}

$\mathrm{Na}$ etapa seguinte, capturamos as imagens apresentadas nos resultados, fizemos uma análise sobre elas, pelo que melhor apresentavam e escolhemos cerca de cinco imagens que também estivessem com melhor resolução.

Durante a análise sobre as principais imagens consideramos as que melhor destacassem suas características com base na escala, promovida pela altitude de vôo, onde nos apoiamos em Cruz (1981) ao falar sobre o processo de interpretação de imagens como as "informações são obtidas por técnicas de observação, desenvolvimentos lógicos e acurados, chegando a conclusões" (Cruz, 1981, p. 8).

\section{Resultados e Discussão}

Os resultados obtidos são uma sequencia de fotografias digitais que mostram os mais variados objetos de estudo destacados conforme a escala gerada pela altitude do vôo.

Nenhuma das imagens sofreu qualquer tipo de modificação ou melhoramento digital, nem mesmo recursos como filtros, para dar ênfase a qualquer objeto.

Distorções para o encaixe das imagens pode gerar mudanças de proporção, bem como o posicionamento da lente, no instante da captura das imagens, portanto as fotografias foram colocadas aqui na tentativa de atenuar estas distorções aparentes. 


\section{OS DESAFIOS DA GEOGRAFIA FÍSICA NA FRONTEIRA DO CONHECIMENTO \\ Instituto de Geociências - Unicamp \\ Campinas - SP \\ 28 de Junho à 02 de Julho de 2017}

Começaremos apresentando as imagens com escalas maiores para menores e nesse sentido concordamos com Panizza e Fonsceca $(2011$, p.33) ao dizer-nos que "A escolha da fotografia ou imagem usada no estudo da paisagem é fundamental e vai interferir no tipo de informação produzida. Ela deve levar em conta o objeto estudado, a escala geográfica e os tipos de imagens disponíveis destacando o que é mais simples de ser observado". Também concordamos com as autoras ao dizernos que as técnicas para interpretação de imagens de forma visual, podem ser usadas tanto nas fotografias aéreas quanto nas imagens de satélite. Nesta pesquisa utilizamos também o termo estratégias, como uma forma de definir as etapas para a realização da leitura das imagens, realizadas visualmente e sem a utilização de instrumentos, como o estereoscópio utilizando basicamente a inferência.

$\mathrm{Na}$ imagem número dois podemos observar o rio Tietê próximo ao aeroporto de Congonhas na decolagem da aeronave. É possível notar que há poucas áreas de vegetação intensa e que a urbanização é um dos pontos fortes da região. Por ter uma escala média, é possível apontar alguns detalhes, como o destaque de edifícios, que despontam em meio à urbanização.

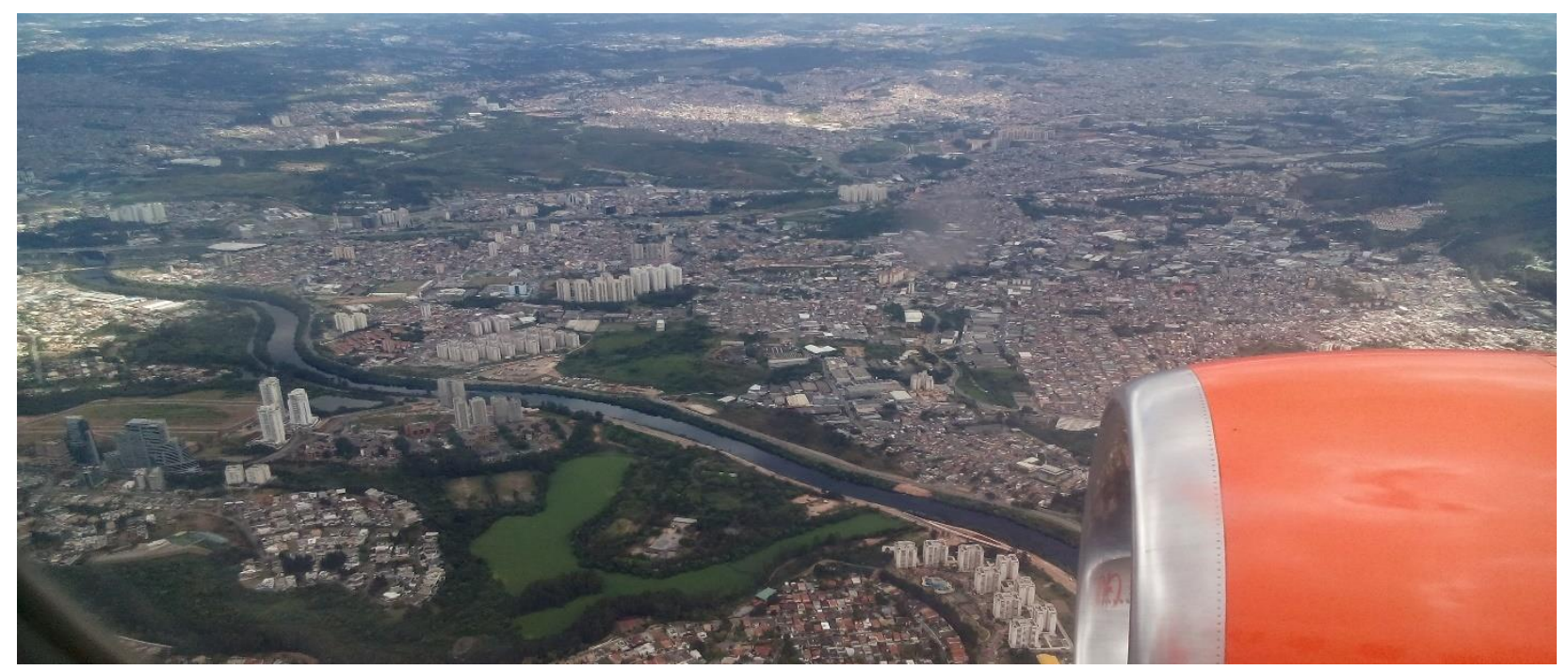

Imagem 2- Rio Tietê, SP.

Novo (1995, p.251) diz que "decomposto analiticamente num processo de identificação do objeto em relação a uma dada categoria", partindo deste princípio a imagem que expõe um contexto geral, naturalemente será decomposto em partes, no processo de interpretação, portanto ao vermos um produto como a imagem três em um primeiro momento observamos um todo, e que com nosso conhecimentos prévios já experienciados, identificamos os demais elementos constituintes do todo como, por exemplo,a imagem número três que mostra a exploração mineral no alto de um morro, bem como a vegetação em maior quantidade. 


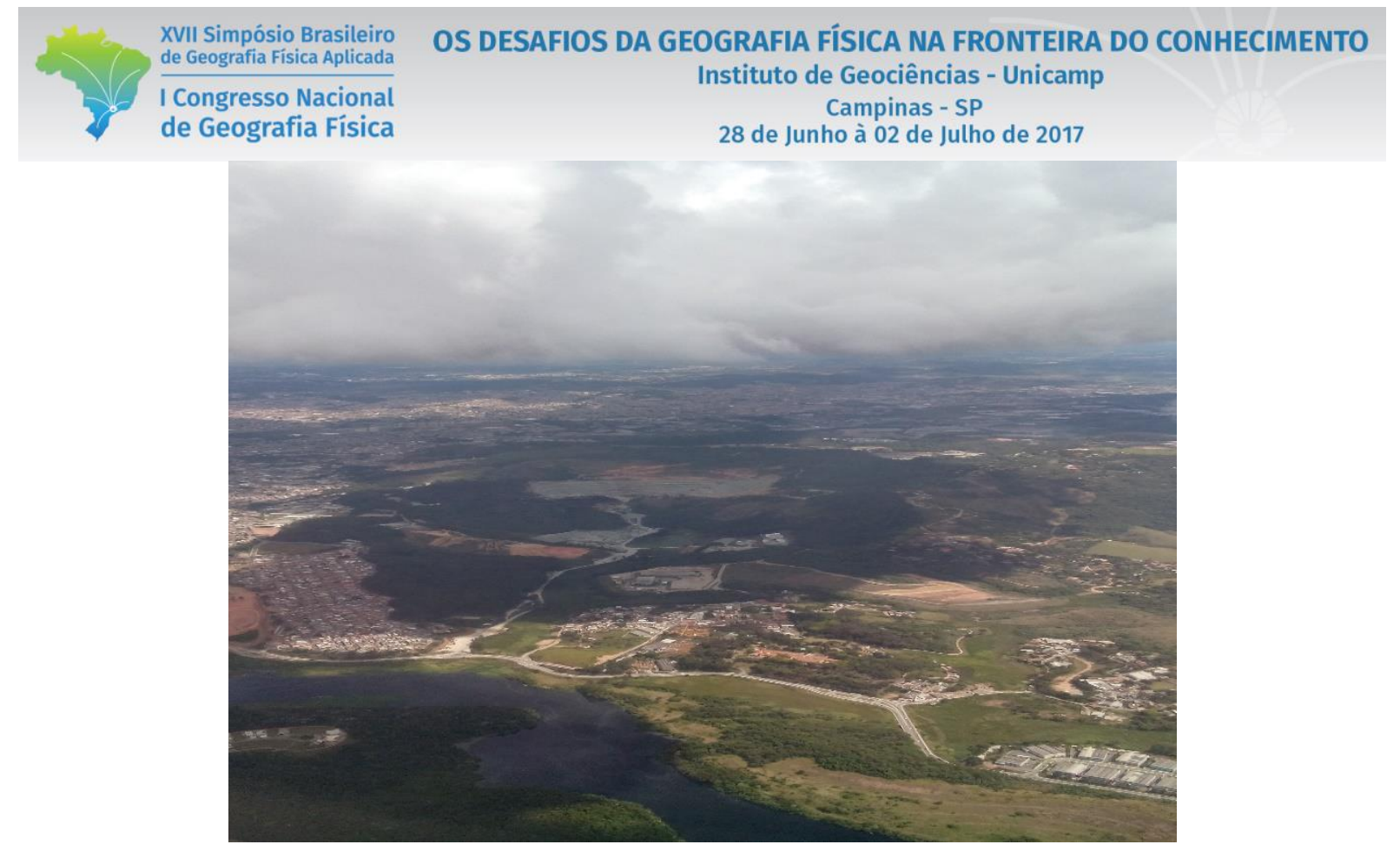

Imagem 3- Exploração mineral.

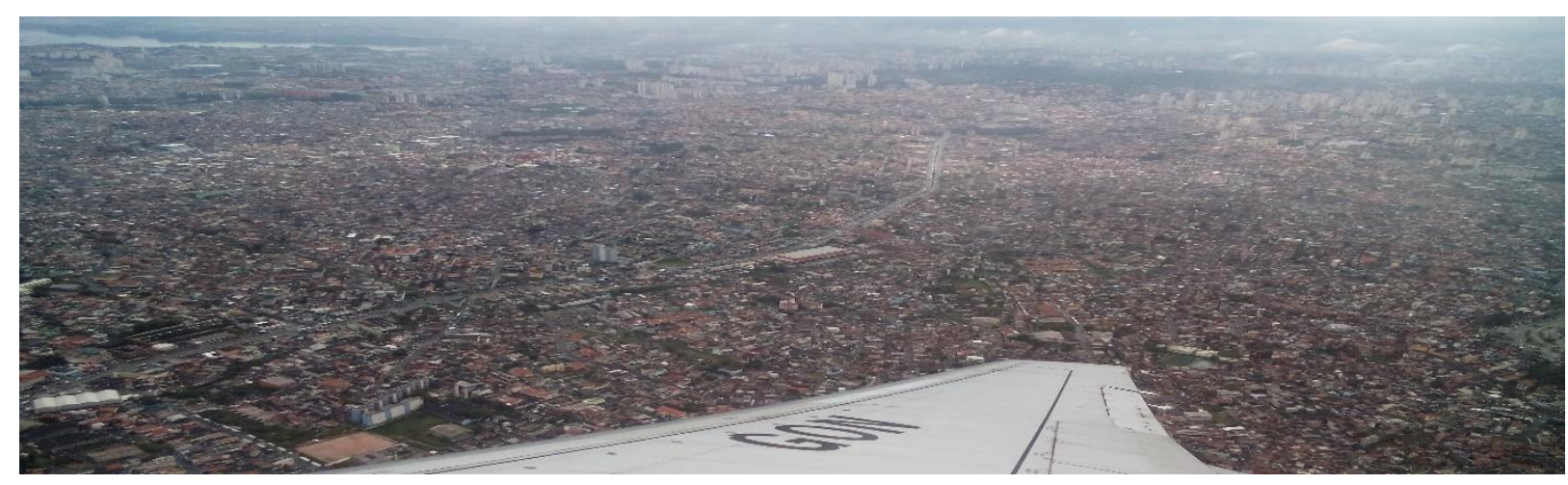

Imagem 4- Adensamento urbano.

A imagem seguinte, de número quatro, apresenta uma escala menor em relação às anteriores, mostrando o adensamento urbano de parte da cidade de São Paulo. Aqui a abstração torna-se mais difícil, e isolando alguns detalhes que se destacam como, pavilhões e uma faixa que "corta" a cidade, pouco se pode reconhecer em uma visão geral.

A imagem número cinco, apresenta as regiões de transição entre norte de Minas Gerais e Goiás. Nela é perceptível o mosaico formado por recorte de vegetação esparsa, em meio ao campo, e em toda a imagem podemos deduzir que há recursos hídricos rodeados por mata ciliar que se estende e divide a fotografia em partes. 


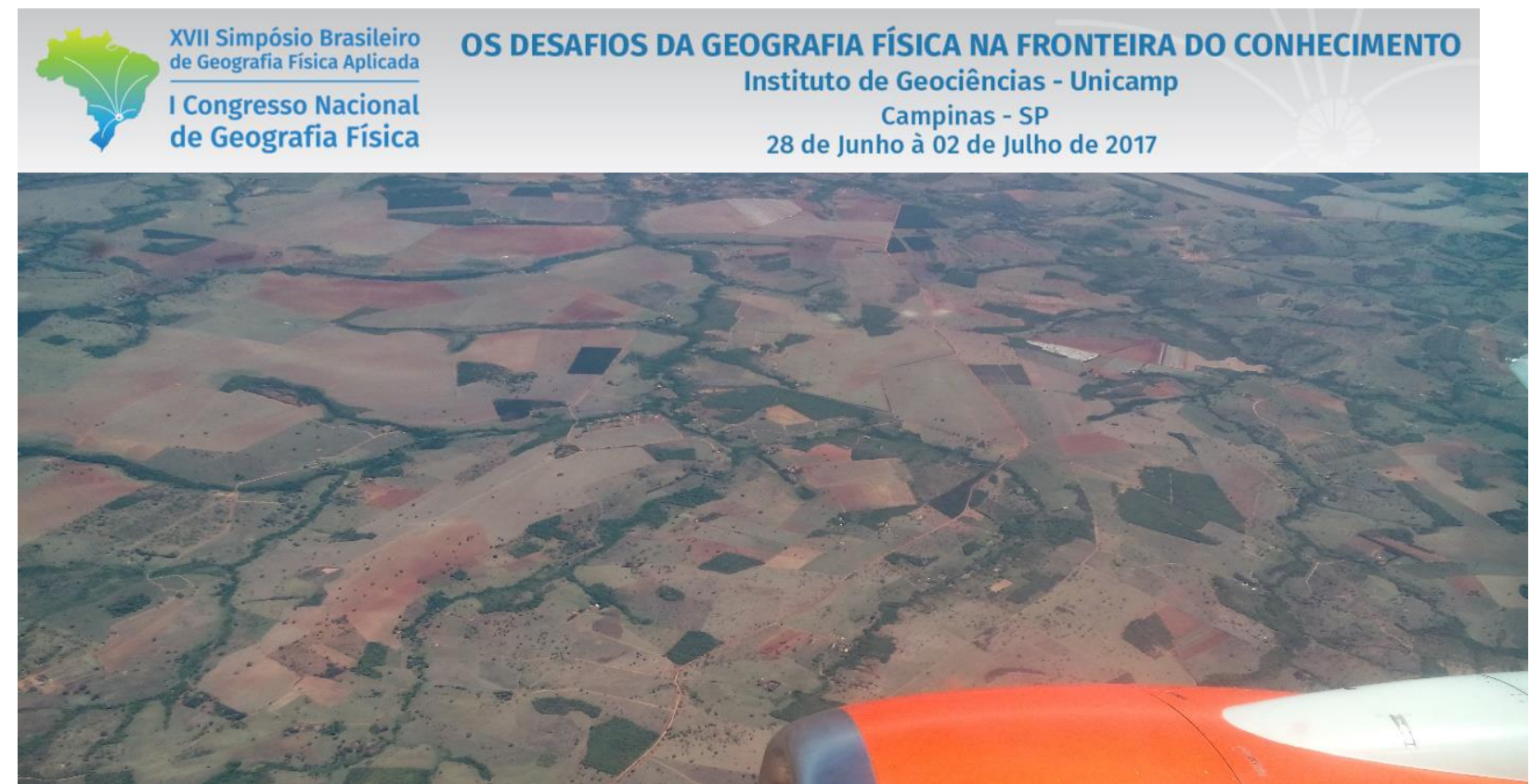

Imagem 5- Mosaico comporto de campo e vegetação.

A imagem número seis assemelha-se a anterior, porém nela observamos o plantio de culturas de forma circular, com base no estilo de irrigação utilizada.

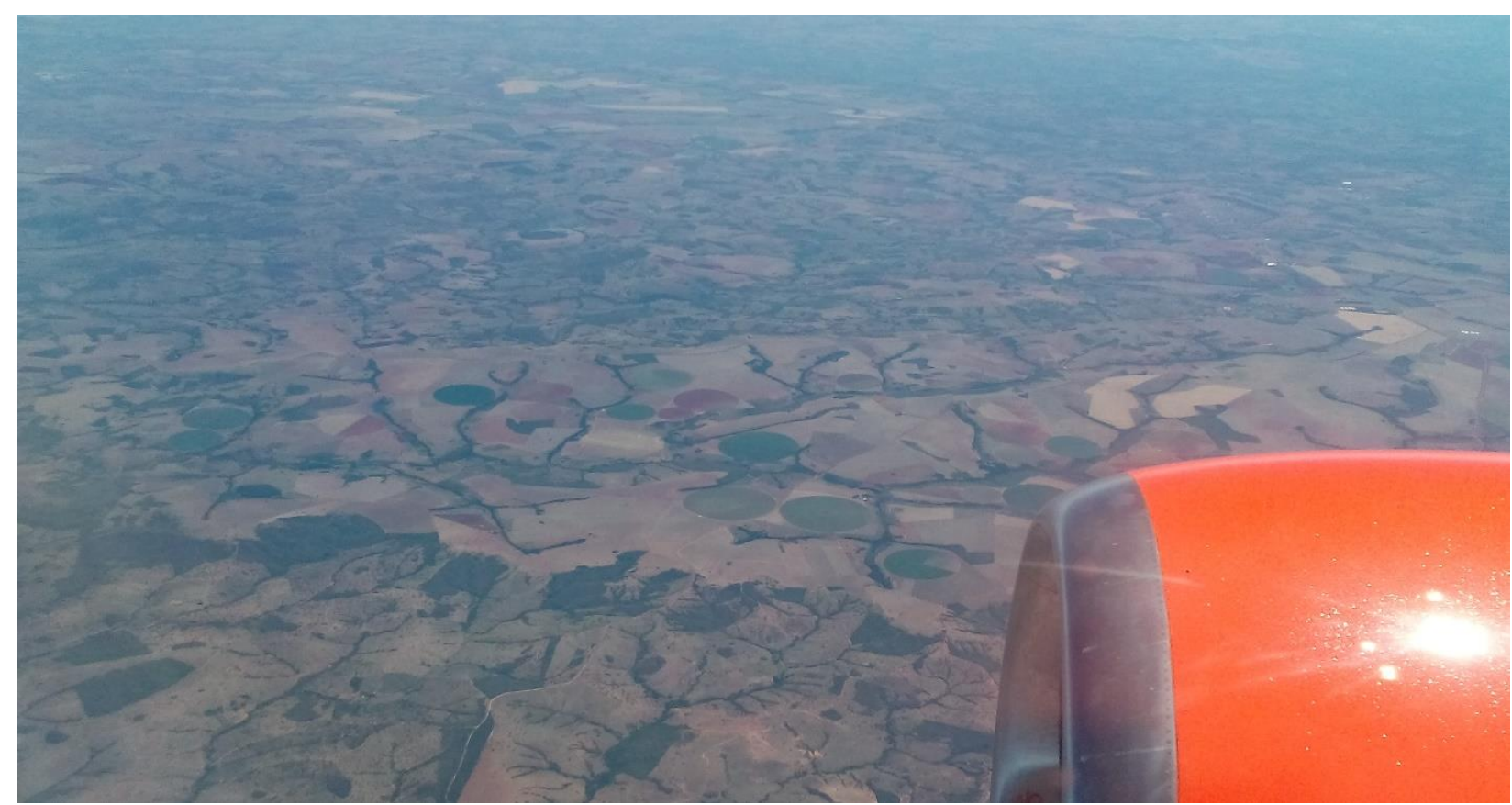

Imagem 6- Plantio circular.

A imagem número sete apresenta uma bacia hidrográfica. Os polígonos nela marcados foram colocados para mostrar onde há urbanização. Há muitas outras, porém com uma dificuldade maior em serem destacadas. 


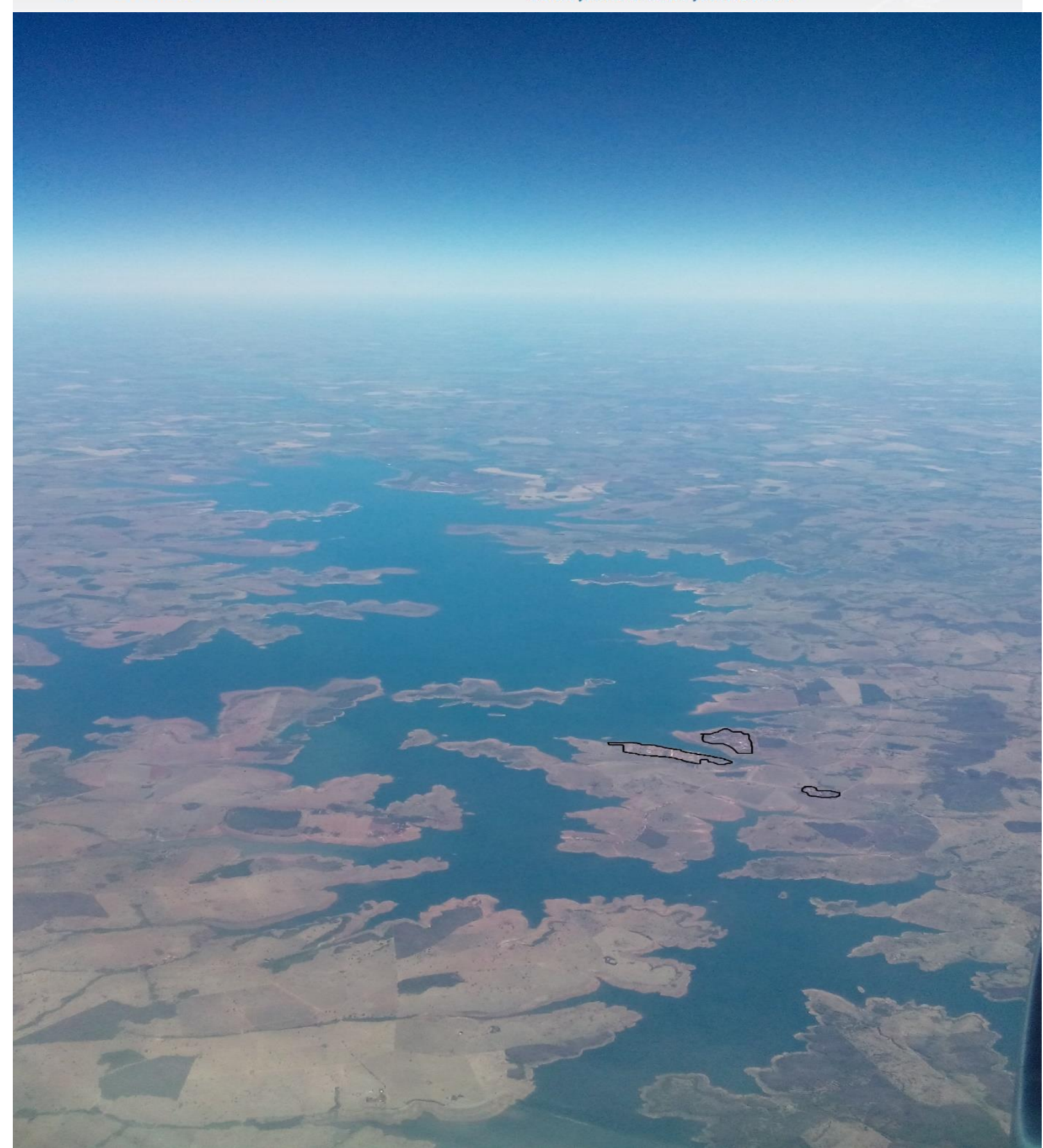

Imagem 7- Bacia hidrográfica.

Os resultados atingiram o objetivo principal proposto, pois com estes recursos conseguimos interpretar de maneira simples e com alto índice de assertividade, os elementos presentes nas imagens, pois a alta resolução da câmera do smartphone utilizado proporcionou uma melhor leitura dos elementos presentes na imagem. 


\section{OS DESAFIOS DA GEOGRAFIA FÍSICA NA FRONTEIRA DO CONHECIMENTO \\ Instituto de Geociências - Unicamp \\ Campinas - SP \\ 28 de Junho à 02 de Julho de 2017}

As noções de escala a partir da altura em que a aeronave se encontra puderam ser utilizadas a partir da observação de riqueza de detalhamento que puderam ou não ser constatados, podendo definir a escala em grande ou pequena.

\section{Considerações Finais}

Na ciência Geográfica, a utilização de imagens cumpre uma importante função para o entendimento sobre o espaço geográfico e com as tecnologias estando disponíveis para grande parte da população brasileira, com ênfase nos dispositivos móveis, estes recursos representam importantes ferramentas para explorar as perspectiva da concepção do espaço físico, e do meio natural.

No mundo contemporâneo, é quase inevitável o auxílio das tecnologias, sendo assim torna-se necessário acompadrar as mudanças que ocorrem, no sentido de procurar diversificar a metodologia utilizada.

Esta pesquisa nos deixou claro que as imagens representam mais do que paisagens, ela fornece informações importantes sobre o espaço, para aquele que souber ler e interpretá-las.

No decorrer das atividades, o uso de imagens digitais mostraram-se importantes ferramentas como recurso metodológico para a análise espacial em diferentes escalas de aproximação, e diferentes temáticas que podem ser percebidas a analisadas, quantitativamente e qualitativamente por aqueles que correspondem a conceitos que fundamentam desenvolvem uma boa leitura e reflexão de imagens.

A disponibilidade de softwares, de imagens de satélites e de equipamentos, como o GPS, radares, barômetros, espectrômetros, supercomputadores, facilitam e dinamizam em muito o trabalho de análise e de pesquisas em várias áreas objeto de estudo dos Geógrafos.

Ainda que não seja possível registro em infravermelho por smartphones, não devemos subjugar a eficiência e o caráter analítico destes produtos, pois sua tecnologia tende a garantir cada vez mais a qualidade destes registros, e apoia-se simplicidade, baixo custo e fácil armazenamento das fotografias. Sendo assim, podemos dizer que a tecnologia e seus avanços contribuíram consideravelmente para elevar a Geografia a um patamar nunca antes imaginado. Fazendo uso não apenas utilizassem as modernas técnicas de geoprocessamento e sensoriamento remoto, mas também do Geógrafo moderno que compreende e sabe como utilizar recursos tecnológicos alternativos para a elaboração e análise do ambiente, da sociedade, e da natureza.

\section{Bibliografia}

CRUZ, Olga. Alguns conhecimentos básicos para a fotointerpretação. In: AerofotoGeografia 25. São Paulo: IGEOG/USP, 198. 
FLORENZANO, Teresa G. Imagens de satélite para estudos ambientais. São Paulo: Oficina de textos, 2002

NOVO, Evlyn M.L. de M. Sensoriamento remoto princípios e aplicações. $2^{\circ}$ ed. São Paulo: Edgard Blücher, 1995.

PANIZZA, Andrea de C.; FONSECA, Fernanda P. GEOUSP - Espaço e Tempo. São Paulo, No 30, pp. 30 - 43, 2011.

PENTEADO Heloísa Dupas. Metodologia do Ensino de História e Geografia. São Paulo: ed. Cortez, 1991

PINCHEMEL, Philippe; PINCHEMEL, Geneviève. La face de la terra. Paris: Armand Colin, 1988.

SANTOS, Milton. Técnica, espaço, tempo: Globalização e meio técnico Cientifico informacional. São Paulo, Hucitec. $1996^{\mathrm{a}}$. 